\title{
SIMULATING A MODIFIED HYBRID APPROACH TO RESOURCE ASSIGNMENT IN A SHARED BILLING AND CLAIMS CALL CENTER
}

\author{
Quinn Conley \\ Analytics Resource Center \\ Westfield Insurance \\ Westfield Center, OH 44251, USA
}

\author{
Mark Grabau \\ Advanced Analytics and Optimization \\ IBM Corporation \\ Westerville, $\mathrm{OH} 43082$, USA
}

\begin{abstract}
Westfield Insurance operates a call center that handles billing and claims calls. The call center has resources dedicated to each call type and hybrid resources that can handle both call types. The use of hybrid resources makes it challenging to predict what impact a staffing change will have on service level metrics. This paper documents the approach, lessons learned, and business impacts of modeling the call center with a discrete event simulation. It also provides a method for using queues and resource sets to model hybrid resources.
\end{abstract}

\section{INTRODUCTION}

Westfield Insurance is one of the top 50 property and casualty insurance companies in the USA. Westfield is headquartered in Westfield Center, Ohio (about 45 miles south of Cleveland and 25 miles west of Akron). It is one of the largest non-public companies in Ohio, with over $\$ 1.6$ billion in annual revenues. Westfield distributes its products through a network of over 1,000 independent agencies. The company actively writes personal insurance in 10 states, commercial insurance in 21 states, and surety in 31 states.

Westfield operates a call center to handle incoming billing and claims calls. The Customer Care Center (CCC) is divided into billing and claims units, each with its own pool of Customer Service Representatives (CSRs). In addition, the call center has CSRs that are able to handle both call types. These resources can be designated-hybrid (primary answer one call type and answer the other call type once it has waited beyond a specified amount of time) or hybrid (answer next call regardless of type - billing or claims). Therefore, resource staffing and call arrivals for each unit have an impact on the service level and abandonment metrics of the other.

The CCC leadership wanted to test proposed changes to the existing staffing model without adversely affecting callers. Since modifying the use of designated-hybrid and hybrid resources would have an unknown impact on service level and abandonment, business process simulation was employed to experiment with different resource scenarios.

Twice a year, the CCC conducts employee training. The training classes can either be billing or claims focused. Prior to selecting a class type to offer and what employees will attend, leadership must assess the current need for resources and the availability of new or existing resources to train or crosstrain. Through simulation experimentation, $\mathrm{CCC}$ leadership gained insight into the impact a training class type would have on service levels and abandonment prior to execution. 


\section{Conley and Grabau}

\section{SIMULATION APPROACH}

A disciplined process mapping approach was used to generate requirements for a simulation model of the billing and claims call center. Business customers participating in the process mapping sessions were asked for the quickest, typical, and longest processing times for each step in the process. These times were then documented as the minimum, mode, and maximum processing times respectively, in order to generate a triangular distribution from which to sample in the simulation. Decision logic and associated probabilities were also collected to ensure accurate process flow and a valid simulation.

Rockwell Automation's Arena Simulation software (Rockwell 2012) was used for this project due to availability and author familiarity. Variance reduction was considered in the simulation model at the start. All attributes were assigned to each entity in the model before entities entered processing. This ensured that the experiment results were not influenced by the random number generation.

The simulation was validated against billing and claims service level (the number of calls answered under a certain number of seconds divided by the total number of calls answered), billing and claims abandonment percentage (the number of calls that abandon divided by the total number of calls received), billing and claims average abandon time, and claims cycle time. Resource utilization was also reported for the as-is model and each to-be experiment conducted.

\section{DATA}

Creating accurate schedules for resources in the model was a critical enabler of service level and abandonment validation. Instead of basing the historical schedule analysis on reported schedules, the authors used log data from actual phone records. The phone records provided the times and durations that each Customer Service Representative (CSR) was logged into the phone system. This approach eliminated the effect of any general "unavailable" time that the CSR was on schedule but not queued to take calls (e.g., training, breaks, or coaching sessions).

Basing the resource schedules on the CSR level phone logs also enabled an accurate representation of what type of hybrid resources were available. Figure 1 displays the number of resources by type that were scheduled in the simulation model. As a data insight, the number and time of call arrivals were compared to the historical staffing levels for CCC as seen in Figure 2. A recommendation was made to modify the scheduled resources to better match the fluctuation of arrivals by time of day and day of week. 


\section{Conley and Grabau}

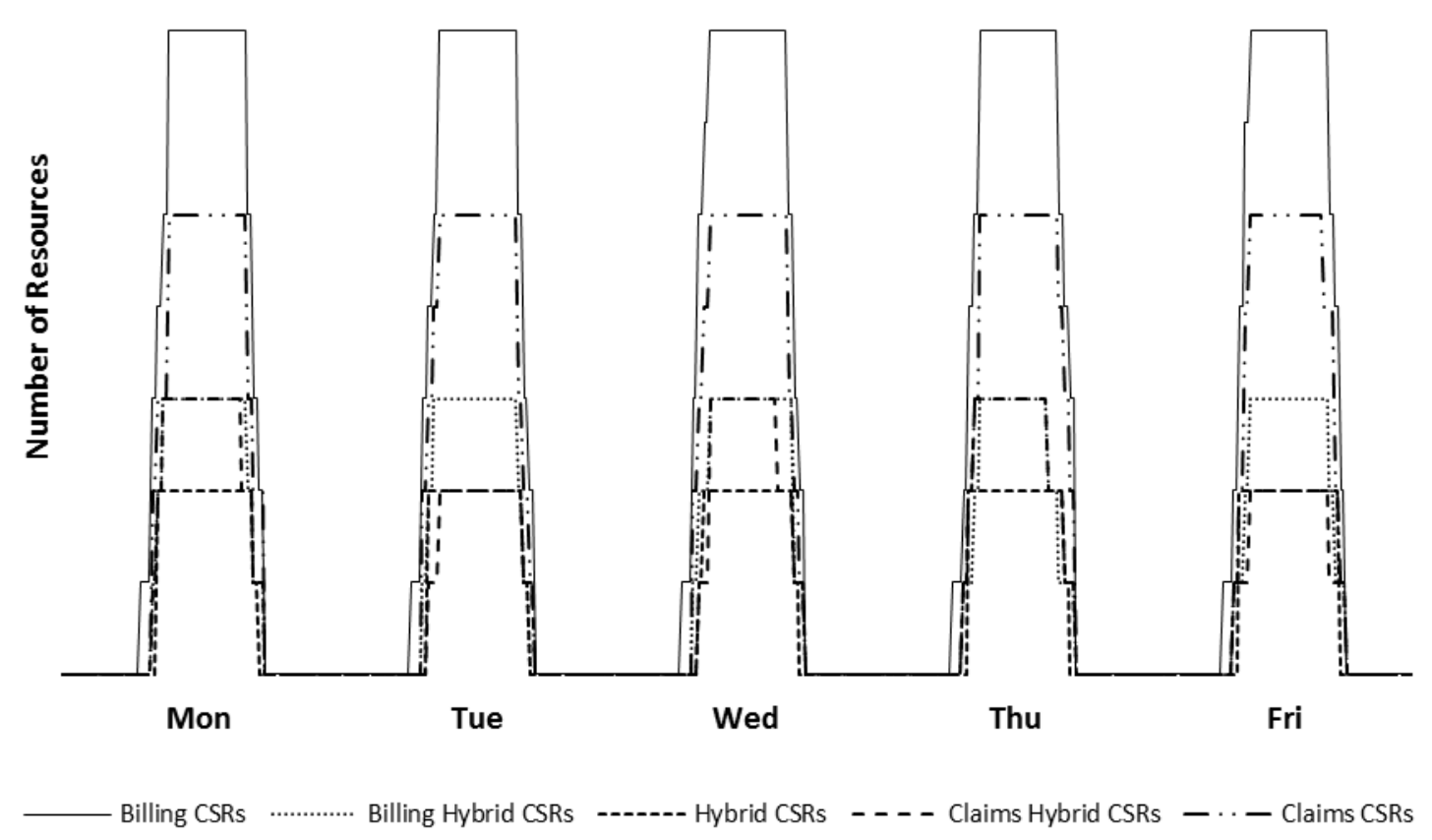

Figure 1: Number of CCC Resources by Type in Fifteen Minute Intervals

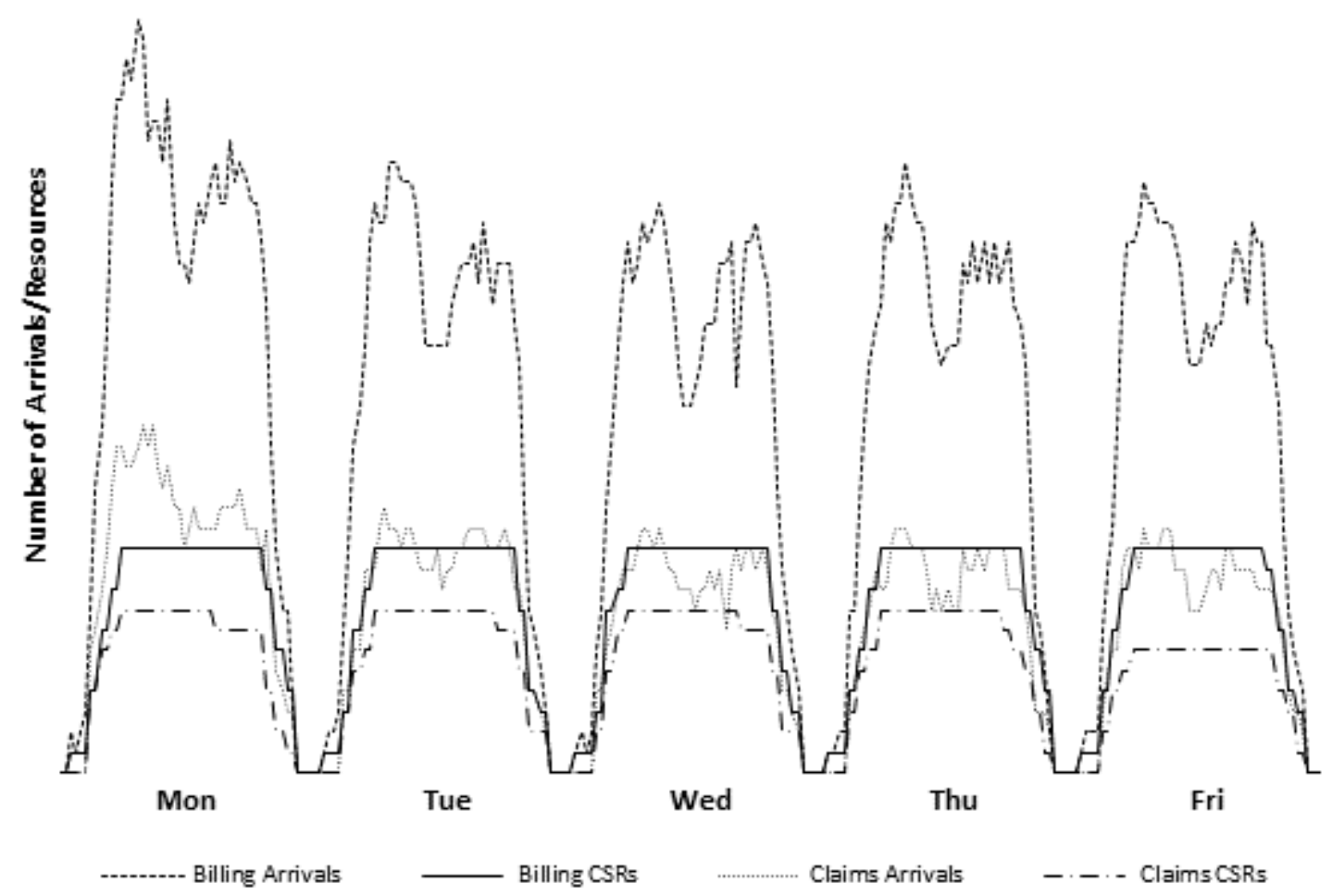

Figure 2: Number of Arrivals vs. Resource Staffing in Fifteen Minute Intervals 


\section{Conley and Grabau}

\section{MODELING THE RESOURCES}

\subsection{Resource Types and Sets}

There were five types of CSR's which were accounted for in the model: billing, billing-hybrid, hybrid, claims-hybrid, and claims. Billing-hybrid and claims-hybrid are the designated-hybrid resources. Designated-hybrids answer their designated call type and they also answer a call of the other type, if the call has waited beyond a specified amount of time. Hybrid resources are CSR's that are equally skilled in both call types and answer the next call of either type.

Four resource sets were created to model the CCC. One set for the primary resources of each type and one set for the overflow resources of each type. The primary billing set consisted of three resources types ordered as follows; billing, billing-hybrid, and hybrid. The overflow billing set consisted of claimshybrid resources. The primary claims set consisted of three resource types with the following order; claims, claims-hybrid, and hybrid. The overflow claims set consisted of billing-hybrid resources.

Arrivals to the CCC are independently generated as either billing or claims calls. Billing and claims calls initially queue at the primary billing or primary claims queues, respectively.

\subsection{Overflow Rules}

Calls that have waited beyond the specified wait time are immediately available to be answered by an idle designated-hybrid resource of the other call type. For example, a billing call that has waited beyond the service level can be answered by a claims-hybrid.

The method for routing calls to the designated-hybrid resources once the service level was not met is a disjointed network with three steps. The process was duplicated for both billing and claims calls.

1. Create a control entity and use it to search the primary queue for the following; a call with a wait time greater than the specified wait time and at least one available designated-hybrid resource of the other call type.

2. Route the control entity based on the value of $\mathbf{J}$ from step 1 . If $\mathrm{J}$ is zero, delay the control entity until the next queue inspection and repeat step 1. If $\mathrm{J}$ is not zero, use the control entity to remove the call from the primary queue, and then delay the control entity until the next queue inspection and repeat step 1.

3. Route the call removed from the primary queue to the overflow queue and seize a resource from the overflow set.

\subsection{Output Statistics}

When a call seizes a resource, a TALLY block is used to track number of calls answered and their associated wait time. A COUNT block is used to track if the call was answered within the specified wait time. Calls that abandoned, along with their associated abandon times, are also tracked using a TALLY block.

\subsection{Abandonment}

Due to the complex interaction between the resource business rules in the CCC and the interdependency of service level and abandonment, a highly accurate model was needed for abandonment. See Conley (in press) for details on how Kaplan-Meier survival analysis was used to model abandonment.

\subsection{Modifying Resources with Excel}

Flexibility to quickly modify the number and type of each resource was built into the model. A Visual Basic for Applications macro was written to read the number and type of resources in fifteen minute intervals from a Microsoft Excel worksheet. The macro then creates the appropriate number of resources by modifying variables in the model that represent the number of CSR's. This eliminated updating the RESOURCE elements individually, eliminating the risk of human error from data entry. The Microsoft 


\section{Conley and Grabau}

Excel interface also enables the user validate the schedule in a tabular form as well as graphically prior to executing a simulation run.

\section{EXPERIMENTS}

Four separate experiments were developed based on the interest of CCC leadership to increase the number and use of designated-hybrid or hybrid resources. The experiments modified the number and type of resources (as shown in Table 1) to achieve the following: Eliminate all types of hybrids, move all designated-hybrids to hybrids, move all resources to designated-hybrids for their respective channel, and move all resources to hybrids. As-is results from the validated model were compared to each to-be experiment to determine impact.

Table 1: Type and Number of Resources by Experiment

\begin{tabular}{|c|c|c|c|c|c|}
\hline Resource & Baseline & No Hybrids & $\begin{array}{c}\text { Designated } \\
\text { to Hybrid }\end{array}$ & $\begin{array}{c}\text { All } \\
\text { Designated }\end{array}$ & All Hybrid \\
\hline Claims & $\mathrm{x}_{1}$ & $\mathrm{X}_{1}+\mathrm{X}_{2}$ & $\mathrm{x}_{1}$ & & \\
\hline Claims-hybrid & $\mathrm{x}_{2}$ & & & $\mathrm{x}_{1}+\mathrm{X}_{2}$ & \\
\hline Hybrid & & & $\mathrm{x}_{2}+\mathrm{y}_{2}$ & & $\mathrm{x}_{1}+\mathrm{x}_{2}+\mathrm{y}_{1}+\mathrm{y}_{2}$ \\
\hline Billing-hybrid & $\mathrm{y}_{2}$ & & & $\mathrm{y}_{1}+\mathrm{y}_{2}$ & \\
\hline Billing & $\mathrm{y}_{1}$ & $\mathrm{y}_{1}+\mathrm{y}_{2}$ & $\mathrm{y}_{1}$ & & \\
\hline
\end{tabular}

\section{RESULTS AND CONCLUSIONS}

Across all experiments, it was clear that hybrid resources of any type decrease abandonment. Removing designated-hybrid or hybrid resources increased abandonment and adding them reduced abandonment for both call types simultaneously. A staffing model with all hybrid resources resulted in the largest improvement in service level and the largest reduction in abandonment for both call types.

Designated-hybrid resources go where the call volume is, which can negatively impact the service level of their designated call type. Answering overflow calls of the other call type makes the designatedhybrids less available to answer incoming calls of their primary type. Since there are nearly twice as many billing calls as claims calls, changing the claims-hybrids to primary claims resources improved the claims service level. This occurred because the resources that were previously claims-hybrids were more available to answer incoming claims calls because they were not answering overflow billing calls, as evidenced by lower utilization numbers.

Designated-hybrid resources have a direct impact in reducing the abandonment percentage of the call type for which they are not designated. Designated-hybrids cannot directly impact the service level for the other call type because the calls they answer have already waited beyond the specified wait time; however, by answering the calls that have waited beyond the specified wait time, they free up primary resources to answer incoming calls more quickly, which improves the service level for the other call type.

Maintaining a call center with a mixed set of resources has implications as far as equal utilization of staff. It was clear in the experiments that designated-hybrid and hybrid resources had higher utilization than primary only resources.

\section{BUSINESS IMPACT}

The simulation model had several impacts on the CCC. The process maps developed and used for the simulation requirements are being leveraged for new employee training. The experiment results influ- 


\section{Conley and Grabau}

enced the decision of CCC leadership to shift all existing designated-hybrid resources to hybrid resources. CCC leadership also initiated a strategy to move toward an all hybrid staffing model. Finally, the results influenced the selection of the call type for the upcoming employee training class.

\section{REFERENCES}

Conley, Q. D. In press. "Simulating Abandonment Using Kaplan-Meier Survival Analysis in a Shared Billing and Claims Call Center." In Proceedings of the 2013 Winter Simulation Conference, Edited by R. Pasupathy, S.-H. Kim, A. Tolk, R. Hill, and M. E. Kuhl. Piscataway, New Jersey: Institute of Electrical and Electronics Engineers, Inc.

Rockwell Automation, Inc. 2012. Arena (Version 14.0). Milwaukee, WI.

\section{AUTHOR BIOGRAPHIES}

QUINN CONLEY is a Business Intelligence Analyst in the Analytics Resource Center at Westfield Insurance. He currently works as an internal, advanced-analytics consultant, focusing on discrete event simulation and predictive modeling. Prior to his current role, Mr. Conley provided analytics support in the rate and profitability management of Westfield's non-standard auto products. Mr. Conley is a graduate of Baldwin-Wallace College in Berea, Ohio; with a B.S. in Mathematics. He will be graduating from Ashland University in Ashland, Ohio in Fall, 2013 with a Master's in Business Administration. His email address is quinnconley@westfieldgrp.com.

MARK GRABAU is an Associate Partner in IBM's Business Analytics and Optimization service line. He leads the North America Advanced Analytics and Optimization practice for the Financial Services Sector at IBM and has over 20 years of experience building advance analytics models supporting the marketing and operational functions of large Financial Services, Retail, and Government organizations. Mr. Grabau has managed large, complex analytics projects while providing technical oversight to model design, development, and deployment. He has published 12 refereed papers on the application of advanced analytics to real-world business problems. Mr. Grabau is a Lean Six Sigma Blackbelt and holds M.S. degrees in Operations Research and Statistics from the Colorado School of Mines and a B.S. in Operations Research from the United States Air Force Academy. His email address is mark.grabau@us.ibm.com. 